\title{
Gas transport and separation with ceramic membranes. Part II. Synthesis and separation properties of microporous membranes
}

\author{
R.J.R. Uhlhorn*, K. Keizer and A.J. Burggraaf \\ Twente University of Technology, Faculty of Chemical Engineering, Laboratory of Inorganic Chemistry, Material Science \\ and Catalysis, P.O. Box 217, 7500 AE Enschede (Netherlands)
}

(Received October 16, 1990; accepted in revised form October 18, 1991).

\begin{abstract}
Non-supported microporous silica (amorphous) and titania thin films were made by the polymeric gel route. The titania system consisted of particles smaller than $5 \mathrm{~nm}$. Reproducible modification of supported $\gamma$-alumina films with silica demands a strict control of every modification step. Silica films of $30-$ $60 \mathrm{~nm}$ thickness on top of and presumably partly inside the $\gamma$-alumina film were realised. The permeabilities of helium and hydrogen through this film are activated, while the propylene permeability was below the detection limit. Separation factors of $\mathrm{a}_{2}-\mathrm{C}_{3} \mathrm{H}_{6}$ mixture are larger than 200 at $200^{\circ} \mathrm{C}$ with a flux for the preferentially permeating hydrogen of $1.6 \times 10^{-6} \mathrm{~mol} / \mathrm{m}^{2}-\mathrm{sec}-\mathrm{Pa}$. The pores must be of molecular dimensions to realise this ( $<1 \mathrm{~nm}$ diameter). Preliminary research shows that changes in the synthesis parameters result in higher activation energies and improved separation properties. The relation between synthesis, resulting microstructure and gas separation properties, however, is not yet fully understood.
\end{abstract}

Keywords: ceramic membranes; diffusion; gas and vapor permeation; gas separations; microporous and porous membranes

\section{Introduction}

In previous articles the synthesis of ceramic $\gamma$-alumina membranes has been presented $[1,2] \cdot \gamma$-Alumina membranes, having a pore diameter of $3 \mathrm{~nm}$, a sharp pore size distribution

Correspondence to : K. Keizer, Twente University of Technology, Faculty of Chemical Engineering, Laboratory of Inorganic Chemistry, Material Science and Catalysis, P.O. Box 217, 7500 AE Enschede (Netherlands)

*Present address: Unilever Research Laboratory, P.O. Box 114,3130 Ac Vlaardingen (Netherlands). and containing no defects have been prepared. A modification method to influence the chemical characteristic of the surface of the membrane and to decrease the pore size has been given [3]. Gas separation with the non-modified as well as the modified membranes is possible by employing Knudsen diffusion [4] and surface diffusion [5]. However, these separations have a relatively low selectivity. Therefore, other separation mechanisms should be considered. In part I of this study the mechanism of multilayer diffusion and capillary con- 
densation was studied [6]. In this article microporous membranes are the subject of study.

Microporous is a term with very different meanings in different technology fields. In membrane technology it is often used to indicate that the membrane contains pores larger than $50 \mathrm{~nm}$. In fields like adsorbent technology and catalysis the term microporous indicates a pore diameter smaller than $2 \mathrm{~nm}$. This is in accordance with the IUPAC definition [7] and so it will be used in this article in this sense.

A pore diameter below $2 \mathrm{~nm}$ could not be obtained by the reservoir modification method, as shown before [3]. This is due to the pore morphology of the $\gamma$-alumina film and the crystallization behavior of the hydroxide species, resulting in pore opening. To obtain a pore diameter below $2 \mathrm{~nm}$ in $\gamma$-alumina thin films, this film should be modified with a thermally stable, non-crystallizing agent.

The obvious choice is silica. Silica is known to be amorphous and thermally stable up to 900 ${ }^{\circ} \mathrm{C}$ [8]. However, its densification behavior is very sensitive to water. Therefore a second choice had to be made. Titania has been selected because it is much less sensitive to water, although it is presumably less thermally stable than silica in terms of devitrification.

In order to obtain microporous silica and titania, a polymeric synthesis route was chosen. Colloidal systems of titania and silica do not yield particles small enough to obtain membrane pore diameters below $2 \mathrm{~nm}[8,9]$. In a single study very small particles, so called $\mathbf{Q}$ particles, with a diameter of $3 \mathrm{~nm}$ could be produced [10]. Polymeric gel synthesis consists of hydrolysis of a metal alkoxide and subsequent or simultaneous polycondensation. This procedure can yield microporous gels under properly selected synthesis conditions $[11,12]$. The differences and similarities with the synthesis of $Q$ sized particles are briefly discussed.

First the synthesis procedure and the most important parameters, as revealed from the lit- erature, are given. The selected synthesis procedure of non-supported titania and silica thin films is then presented. The resulting microstructure is analysed and some problems arising in micropore analysis are addressed. The chemical and thermal stabilities of the thin nonsupported films have also been studied. The synthesis of thin supported layers focusses on silica, since only preliminary results are obtained with titania modified supported $\gamma$-alumina films. The location of the silica with respect to the $\gamma$-alumina film is studied by scanning Auger microscopy (SAM) and X-ray photo spectroscopy (XPS). Finally the excellent transport and separation properties of the silica modified supported $\gamma$-alumina thin films are presented. It becomes clear, that characterization of this kind of microporous systems is extremely difficult. Therefore this article is concluded with some possibilities for further research.

\section{Theory}

The polymeric gel synthesis consists of hydrolysis and condensation reactions, which can be either acid or base catalysed. The most probable mechanisms for these reactions are given in Figs. 1 and 2 [13]. The key mechanism is that in the hydrolysis step a silanol is formed which in turn can form a polysilicate in the condensation step. In this way inorganic polymers are formed. The degree of polymerization will depend on the ratio of the hydrolysis rate over the condensation rate.

Figure 1 shows that the acid catalysed hydrolysis proceeds through an electrophilic attack of the $\mathrm{H}^{+}$ion. This means that the reactivity decreases as the number of $\mathrm{OR}$ groups decreases with the progression of hydrolysis [14-16]. The probability of formation of fully hydrolysed silicon, $\mathrm{Si}(\mathrm{OH})_{4}$, is thus small. The hydrolysis reaction is the rate determining step. The condensation reaction will start before the 
Hydrolysis:

$\mathrm{H}^{+}+>\mathrm{Si}-\mathrm{OR} \underset{\text { fast }}{\longrightarrow}>\mathrm{Si}-\stackrel{+}{-} \underset{\mathrm{R}}{-\mathrm{H}}$

$>\mathrm{Si}-\stackrel{+}{-} \underset{\mathrm{R}}{-}+\mathrm{H}_{2} \mathrm{O} \underset{\text { slow }}{\longrightarrow}>\mathrm{Si}-\mathrm{OH}+\mathrm{ROH}+\mathrm{H}^{+}$

Condensation:

$\mathrm{H}^{+}+>\mathrm{Si}-\mathrm{OR} \underset{\text { fast }}{\rightleftharpoons}>\mathrm{Si}-\stackrel{+}{-} \underset{\mathrm{R}}{-\mathrm{H}}$

$>\mathrm{Si}-\mathrm{OH}+>\mathrm{Si}-\stackrel{+}{\mathrm{O}} \backslash \underset{\mathrm{R}}{-} \underset{\text { slow }}{\longrightarrow}>\mathrm{Si}-\mathrm{O}-\mathrm{Si} \leq+$

$\mathrm{ROH}$

Fig. 1. Acid catalysed hydrolysis and condensation reactions of a silicon alkoxide.

Hydrolysis:

$\mathrm{OH}^{-}+>\mathrm{Si}-\mathrm{OR} \underset{\text { slow }}{\longrightarrow}>\mathrm{Si}-\mathrm{OH}+\mathrm{OR}^{-}$

$\mathrm{OR}^{-}+\mathrm{H}_{2} \mathrm{O} \underset{\text { fast }}{\longrightarrow} \mathrm{ROH}+\mathrm{OH}^{-}$

Condensation

$>\mathrm{Si}-\mathrm{OH}+\mathrm{OH}^{-} \underset{\text { fast }}{\longrightarrow}>\mathrm{Si}-\mathrm{O}^{-}+\mathrm{H}_{2} \mathrm{O}$

$>\mathrm{Si}-\mathrm{O}^{-}+>\mathrm{Si}-\mathrm{OR} \underset{\text { slow }}{\longrightarrow}>\mathrm{Si}-\mathrm{O}-\mathrm{Si}<+\mathrm{RO}^{-}$

Fig. 2. Base calalysed hydrolysis and condensation reactions of a silicon alkoxide.

silicon alkoxide is completely hydrolysed. Silicon alkoxide molecules polymerize with nonhydrolysed alkoxyl groups. Thus the acid catalysed hydrolysis-condensation reactions yield relatively small polymers, in which the degree of crosslinking is low [17]. The gyration radius of these small molecules is typically in the order of $1.5-1.7 \mathrm{~nm}[16,17]$.

The base catalysed hydrolysis reaction proceeds through the nucleophilic substitution of $\mathrm{OH}^{-}$ions (Fig. 2). The reactivity increases as the number of OR groups decreases [14-16].
The silicon alkoxide will be completely hydrolysed. The condensation reaction is the rate determining step and the more crosslinked species will grow at the expense of the smaller ones [17]. Therefore the base catalysed hydrolysiscondensation reactions yield large, highly crosslinked polymers [14-17]. Gels formed from these large polymers contain large pores [8]. The base catalysed synthesis will not result in microporous materials due to the large, highly crosslinked particles. It must be concluded that only the acid catalysed reactions can result in microporous materials.

The most important factors controlling the microstructure of silica gels made by the acid catalysed polymeric gel route are:

-The alcohol content;

-The water content;

-The amount and type of acid.

Normally water and metal alkoxides are mixed in alcohol, because they are insoluble in each other. Obviously the higher the alcohol content, the lower the metal alkoxide concentration, resulting in reduction of the polymerization rate $[14,18]$.

The effects of the water content are pronounced. If more water is added, the hydrolysis rate increases, while the condensation rate is retarded (Fig. 1). The formation of more crosslinked products is favored [14-16]. At very high water content (molar ratio $\mathrm{H}_{2} \mathrm{O}: \mathrm{Si}(\mathrm{OR})_{4}>10$ ) spherical or highly crosslinked particles are produced.

The effect of the amount of acid is not clear from the literature. In general it can be stated that the $\mathrm{pH}$ should be below $2[8,12-16]$. The type of acid is important, because the anions presumably have marked effects. Especially the gelling time is a strong function of the type of acid (e.g. 35 days for a $\mathrm{HCl}$ catalysed sample, but only 16 days for an acetic acid catalysed sample [13]).

In summary it can be concluded that by changing the synthesis parameters it is possi- 
ble to control the properties of the resulting gel, although the connection is not clear yet. However, this holds especially for bulk gels, on which most studies have been performed. It is likely though, that structural evolution in thin films is different from that in bulk gels [18-20]. During deposition of a thin film, a rapid increase in concentration, due to evaporation, will occur. This will significantly increase reaction rates. In addition, a competition is established between evaporation (developing capillary forces, thus compacting the structure) and continuing condensation reactions (stiffening the structure). Studies of these processes are of recent date [18-20]. Microstructural development in thin films as a function of the above mentioned synthesis parameters is still very poorly understood, let alone controlled in a systematic way.

\section{Experimental procedures}

For the preparation of silica and titania, tetraethylorthosilicate (TEOS) and titania titanium isopropoxide (TIP) were used, respectively. Water and nitric acid were used in an ethanol solution. The exact quantities are given in the next section. TEOS was added to a vigorously stirred ethanol solution by slow pouring. Diluted acid solutions were added in the same way. The mixture was then heated to 90 ${ }^{\circ} \mathrm{C}$ as fast as possible and kept there for $3 \mathrm{hr}$. A reflux cooler prevented evaporation. The preparation of titania is more difficult. All the glass equipment should be thoroughly dry, because TIP is very sensitive to traces of moisture. TIP is poured into half of the necessary amount of ethanol, while stirring vigorously. The other half of the ethanol is mixed with the diluted acid solution and then added dropwise to the TIP/ethanol solution while stirring vigorously. No heating is required.

Non-supported silica and titania thin films were obtained by pouring the obtained solu- tions immediately after preparation in a polypropylene dish. The liquid films were dried overnight in ambient atmosphere. The heat treatment varied from sample to sample; full details are presented in the next section. The modification of $\gamma$-alumina supported thin films with silica proved to be very critical.

Non-supported films were analysed by $\mathrm{N}_{2}$ adsorption-desorption measurements using a Micromeritics ASAP 2400, by Ar adsorption (Omnisorp 360), differential scanning calorimetry (DSC, Stanton Redcroft) and XRD (Guinier, Enraf/Nonius camera). Silica modified $\gamma$-alumina thin films were analysed by $\mathrm{X}$ ray photo spectroscopy (XPS, Kratos XSAM 800), scanning Auger microscopy (SAM, Perkin Elmer phi 600) and SEM/EDX using a JEOL JSM 35 CF instrument. Gas permeability and separation data were collected with the equipment described previously $[3,6,21]$.

\section{Results and discussion}

\section{Non-supported microporous films}

To gain more insight in the experimental limits within which microporous materials could be obtained, several compositions were tested. The results are summarized in Table 1. All titania samples were calcined at $300{ }^{\circ} \mathrm{C}$

TABLE 1

The composition of several silica and titania solutions used in the preparation of non-supported polymeric gels, and the resulting pore radius as determined by $\mathrm{N}_{2}$ adsorption desorption

\begin{tabular}{|c|c|c|c|c|c|c|c|c|c|}
\hline \multirow[t]{2}{*}{ Code } & \multicolumn{2}{|c|}{$\mathrm{M}(\mathrm{OR})_{4}$} & \multicolumn{2}{|c|}{ EtOH } & \multicolumn{2}{|l|}{$\mathrm{H}_{2} \mathrm{O}$} & \multicolumn{2}{|l|}{$\mathrm{HNO}_{3}$} & \multirow{2}{*}{$\begin{array}{l}\text { Pore } \\
\text { radius } \\
(\mathrm{nm})\end{array}$} \\
\hline & $\mathrm{ml}$ & ratio $^{\mathrm{R}}$ & inl & ralio & ml & ratio ${ }^{a}$ & $\mathrm{ml}$ & ratio ${ }^{a}$ & \\
\hline Til & 15 & 1.0 & 150 & 51 & 1 & 0.9 & $1(4 M)$ & 0.06 & $<1$ \\
\hline $\mathrm{Ti} 2$ & 15 & 1.0 & 150 & 50 & 2.5 & 2.5 & $2(2 \mathrm{M})$ & 0.08 & $<1$ \\
\hline $\mathrm{Ti} 3$ & 15 & 1.0 & 60 & 20 & 2.5 & 3.0 & $1(2 \mathrm{M})$ & 0.08 & 3. \\
\hline Si1 & 21 & 1.0 & 21 & 3.8 & 8 & 4.6 & M) & 0.09 & $<1$ \\
\hline $\mathrm{Si2}$ & 21 & 1.0 & 21 & 3.8 & 11 & 6.5 & $8(1 \mathrm{M})$ & 0.09 & $<1$ \\
\hline $\mathrm{Si3}$ & 21 & 1.0 & 21 & 3.8 & 4 & 2.3 & $4(2 M)$ & 0.09 & $<1$ \\
\hline
\end{tabular}

${ }^{a} \mathrm{Mol} / \mathrm{mol}$ metal (Si or Ti).

${ }^{b}$ Cylindrical shape. 
(heating rate $12{ }^{\circ} \mathrm{C} / \mathrm{hr}$ ), kept there for three hours and cooled down (rate $12^{\circ} \mathrm{C} / \mathrm{hr}$ ) to 150 ${ }^{\circ} \mathrm{C}$. The silica samples were calcined at $400{ }^{\circ} \mathrm{C}$ (heating rate $25^{\circ} \mathrm{C} / \mathrm{hr}$ ), kept there for three hours and cooled down (rate $25^{\circ} \mathrm{C} / \mathrm{hr}$ ) to 250 ${ }^{\circ} \mathrm{C}$. In the literature, a recipe of $2 \mathrm{~mol} \mathrm{H}_{2} \mathrm{O} / \mathrm{mol}$ $\mathrm{Si}$ and $0.05 \mathrm{~mol} \mathrm{acid} / \mathrm{mol} \mathrm{Si}$ is frequently used. In one study the acid content was increased to $0.4 \mathrm{~mol} / \mathrm{mol} \mathrm{Si} \mathrm{[8].} \mathrm{Table} 1$ shows that in the present study the acid-silica and the water-silica ratios are comparable to those in the literature. For titania there is no reference known in literature. However, Livage and Henry [22] developed a semi-quantitative model to predict the chemical reactivity of several metals in relation to each other. From this model, it follows that the hydrolysis as well as the condensation rates for titanium alkoxide are higher than for silicon alkoxide. Therefore, the titania should be prepared with lower water contents and higher alcohol contents in comparison with the silica preparation in order to obtain similar results. It is shown below that the predictions based on the model of Livage and Henry [22] are experimentally verified. The results are summarized in Table 1.

Figure 3 presents illustrative examples of $\mathrm{N}_{2}$

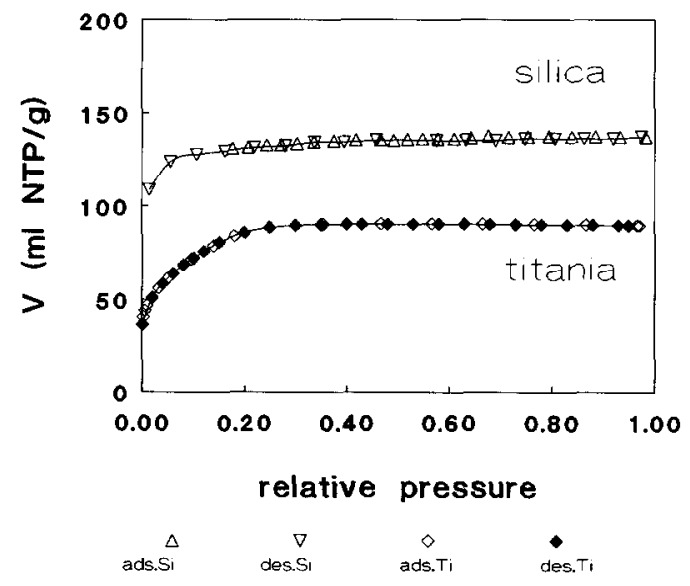

Fig. 3. $\mathrm{N}_{2}$ adsorption-desorption isotherm at $77 \mathrm{~K}$ of microporous silica and titania, determined directly after preparation. adsorption-desorption isotherms of silica and titania samples. So-called type I isotherms [7] are obtained, which are characteristic for microporous materials. If the pore diameter becomes smaller than $2 \mathrm{~nm}$, the concept of multilayer adsorption is physically meaningless. Adsorption in these pores will not give rise to hysteresis (Kelvin's law is not applicable anymore). The volume of the pores is simply filled ('micropore filling' $[7,23]$ ). Table 2 shows, that all silica samples exhibit this type of isotherm. The same holds for the titania samples, except sample Ti3 (see Table 1, last column). Here à high water content and low alcohol content were used. This will lead to faster hydrolysis and condensation reactions, resulting in more branched polymers, as predicted from the model of Livage and Henry [22]. This results in pores larger than $2 \mathrm{~nm}$.

The silica samples were subjected to dynamic laser scattering experiments in an attempt to determine the particle size. No data could be obtained, because the particle size is below the detection limit of this technique ( 5 $\mathrm{nm}$ ). It can only be concluded that the polymeric silica particles are smaller than $5 \mathrm{~nm}$, in accordance with predictions from the literature [16].

Table 1 only shows that the samples are mi-

\section{TABLE 2}

Surface areas and pore radii of several non-supported silica thin films as determined by argon adsorption measurements; the codes correspond to those in Table 1

\begin{tabular}{|c|c|c|c|}
\hline Code & $\begin{array}{l}\text { BET surface } \\
\left(\mathrm{m}^{2} / \mathrm{g}\right)\end{array}$ & $\begin{array}{l}\text { Pore } \\
\text { radius } \\
(\mathrm{nm})\end{array}$ & Remarks \\
\hline Sil & 450 & 0.75 & measured directly after preparation \\
\hline $\mathrm{Si} 2$ & 286 & 0.85 & measured directly after preparation \\
\hline Si1 & $\sim 10^{\mathrm{a}}$ & - & $\begin{array}{l}\text { sample exposed to ambient air for } \\
2 \text { months }\end{array}$ \\
\hline $\mathrm{Si} 2$ & $\sim 40^{a}$ & 1.0 & $\begin{array}{l}\text { sample exposed to ambient air for } \\
2 \text { months }\end{array}$ \\
\hline
\end{tabular}

'Corrected for the outer surface area. 
croporous. The size of the pores cannot be calculated from the $\mathrm{N}_{2}$ adsorption-desorption isotherms, as presented in Fig. 3. However, an estimate of the micropore size is possible by accurate adsorption measurements at relative pressures up to 0.2 [23]. The correct interpretation of these adsorption data is still debatable [23]. On a comparative basis it is a suitable technique as has been shown by Dubinin and others [24-26].

For some silica samples shown in Table 1, the BET surface and the pore radius, calculated using the model described in [26], are given in Table 2. These were determined from accurate Ar adsorption measurement at $77 \mathrm{~K}$ and an initial vacuum of $10^{-7}$ atm. The error margin is substantial (at least $20 \%$ ). Still it can be seen that the samples Si1 and Si2 contain micropores, if the measurement is performed directly after preparation. These micropores are relatively large, while the BET surfaces are relatively small. Note that the BET surface has no physical meaning in micropore analysis and serves for comparison only. The sample with the highest water content ( $\mathrm{Si} 2$ ) also has the largest pore size and the lowest BET surface. This might indicate that increasing the water content also increases the mean pore diameter. It is also possible though, that this sample contains more very small pores $(<0.4 \mathrm{~nm})$ than sample Si1. These very small pores are not accessible for the argon molecule and do not contribute to the BET surface.

Also included in Table 2 are samples, that were exposed to ambient air for two months. After renewed heat treatment at $400{ }^{\circ} \mathrm{C}$, only very low BET surfaces could be detected. This means all the micropores are too small for the argon molecules to penetrate. Presumably the thin silica films have densified under influence of the ambient air and the subsequent heat treatment. In literature the densification of silica under influence of water (vapor) is a wellknown effect [8]. Due to the presence of water vapor rearrangement of surface groups occurs [8], leading to a more dense silica. This process is accelerated at higher temperatures. Presumably this process also occurred with the thin silica films. They densified due to prolonged exposure to the water vapor in the atmosphere.

The thermal stability of silica was tested by $\mathrm{XRD} /$ Guinier (from 20 to $800^{\circ} \mathrm{C}$ ) and DSC (from 20 to $900^{\circ} \mathrm{C}$ ). The Guinier picture did not show any diffraction pattern, indicating the absence of a crystallised phase. DSC measurements also did not show any crystallization peaks up to $900^{\circ} \mathrm{C}$. Consequently it can be concluded, that silica thin films are X-ray amorphous and thermally stable with respect to crystallization up to $900{ }^{\circ} \mathrm{C}$. (These experiments do not demonstrate stability of microporous structure of the amorphous silica to 900 ${ }^{\circ} \mathrm{C}$, however.) This is in agreement with the literature [8].

Table 3 shows the results of the XRD Guinier measurement for titania thin films. It can be seen that above $300{ }^{\circ} \mathrm{C}$ a crystalline phase is detected. The anatase phase recrystallises around $600{ }^{\circ} \mathrm{C}$ to form the rutile phase. This is the stable phase for titania. DSC confirmed these results. A crystallisation peak around 300 ${ }^{\circ} \mathrm{C}$ was detected. Finally $\mathrm{N}_{2}$ adsorption-desorption plots of titania samples, heated to 400 ${ }^{\circ} \mathrm{C}$, showed a hysteresis between the adsorption and desorption branch. The type I isotherm converts to a type IV isotherm, characteristic of mesoporous materials. The

\section{TABLE 3}

Temperatures at which crystalline phases of titania could be detected by the X-ray Guinier method; the codes corresponds to those in Table 1

\begin{tabular}{lll}
\hline Code & $\begin{array}{l}\text { Anatase } \\
\left({ }^{\circ} \mathrm{C}\right)\end{array}$ & $\begin{array}{l}\text { Rutile } \\
\left({ }^{\circ} \mathrm{C}\right)\end{array}$ \\
\hline Ti1 & $295-655$ & $600-800$ \\
Ti2 & $320-800$ & $660-800$ \\
\hline
\end{tabular}


corresponding mean pore diameter is $4 \mathrm{~nm}$, assuming cylindrical pores. It must be concluded that titania crystallises around $350-400{ }^{\circ} \mathrm{C}$, causing the pore diameter to grow.

A HTEM picture, presented in Fig. 4, and an electron diffraction pattern of one of the particles in Fig. 4, offered a slightly different view. The titania sample as shown in Fig. 4 was calcined at $150{ }^{\circ} \mathrm{C}$. Still the particles show a lattice image, indicating a crystalline material. The electron diffraction pattern supports this observation. Figure 4 shows that anatase particles are obtained with a size of approximately $3 \mathrm{~nm}$. This is in apparent contradiction with the XRD/Guinier photo, where no crystalline phase was detected below $300{ }^{\circ} \mathrm{C}$. However, if the particle size is smaller than $5 \mathrm{~nm}$ in one dimension, as in this case, it will appear amorphous to X-ray techniques. The observation of very small titania particles is in agreement with very recent reports on so-called $Q$ particles of titania [10]. The synthesis parameters are apparently such that very small crystalline particles are obtained. Upon increasing the temperature, the particles start to grow. Around 300 ${ }^{\circ} \mathrm{C}$ they have become so large that they are detectable by XRD.

Surprisingly nano-sized particles are obtained by the polymeric gel route, probably due to high water contents. Analogous to the formation of discrete silica particles at very high water contents, presumably discrete titania particles are formed, e.g. by crystallisation of the amorphous material formed in a preceding step.

\section{Supported microporous films}

An exact description of the procedure for modifying supported $\gamma$-alumina thin films with silica proved necessary, because slight (often non-recorded) changes can lead to pronounced (often non-reproducible) effects, which is demonstrated later. The understanding of the interaction between synthesis parameters, film
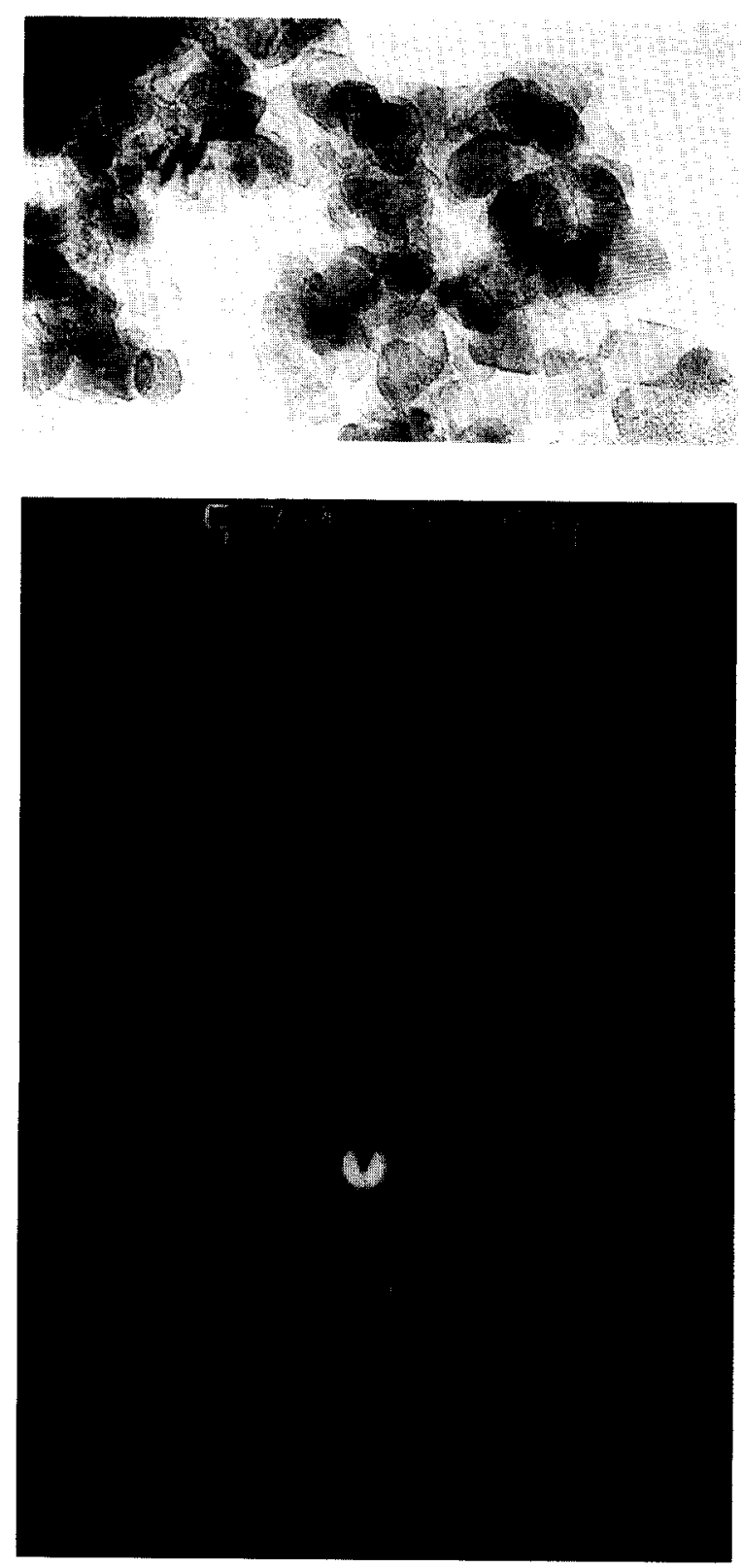

Fig. 4. High resolution TEM picture of a non-supported titania film, microtomed to obtain a sufficiently thin sample. The electron diffraction pattern indicates the anatase phase.

formation, resulting microstructure and transport and separation properties is still in its infancy. It is therefore important to start the ex- 
periments from a well defined position. All the membranes in this section were therefore prepared by a standard procedure which is under patent application [21]. All non-modified $\gamma$-alumina supported thin films showed Knudsen diffusion behavior, with a mean permeability of $1.2 \times 10^{-5} \mathrm{~mol} / \mathrm{m}^{2}$-sec-Pa for helium at $25^{\circ} \mathrm{C}$ [32]. This number will be used as a reference for the remainder of this section.

After modification the silica modified $\gamma$-alumina system was charactcrized by SEM/EDX, XPS and SAM. A cross-section of the $\gamma$-alumina supported thin film was scanned for its silica content by EDX. SEM photographs before and after modification showed that the $\gamma$ alumina film thickness did not increase by more than $100 \mathrm{~nm}$ due to the modification. This indicated silica was present either as a very thin film on top of the $\gamma$-alumina or inside the pores of the $\gamma$-alumina. Figure 5 presents the results of the EDX scan. It shows, that silica is solely found in the upper part of the $\gamma$-alumina very near the top. The resolution of this technique is not better than about $0.5 \mu \mathrm{m}$, so exact location of the silica proved impossible.

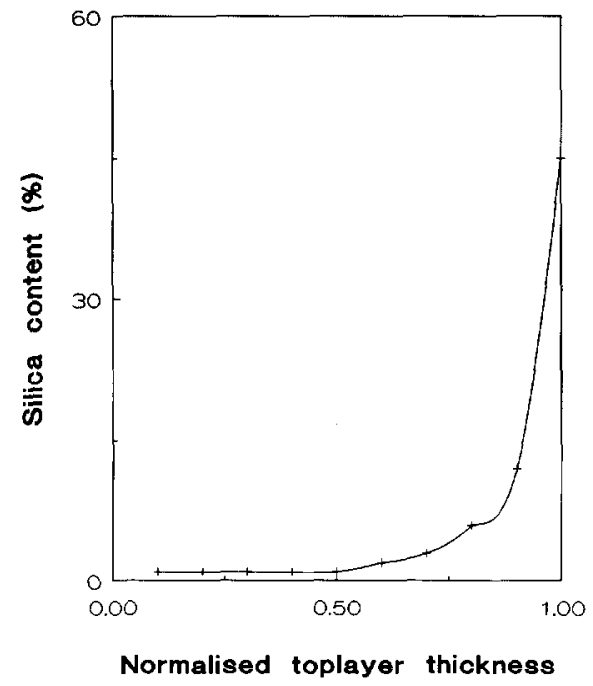

Fig. 5. EDX scan of silica content in a $5 \mu \mathrm{m}$ thick $\gamma$-alumina supported thin film, determined on a cross-section of this supported film.
XPS and SAM are much more sensitive surface analysis techniques, which can analyse compositions in layer thicknesses of $5 \mathrm{~nm}$ or less $[27,28]$. XPS is preferred in the measurements on non-conductive materials because this method uses photons instead of electrons.

Figures 6 and 7 present XPS and SAM sputter profiles of a silica modified $\gamma$-alumina system. It can be seen that until about $30 \mathrm{~nm}$ only silicon is present. After these $30 \mathrm{~nm}$, an aluminium signal is detected. This signal rises,

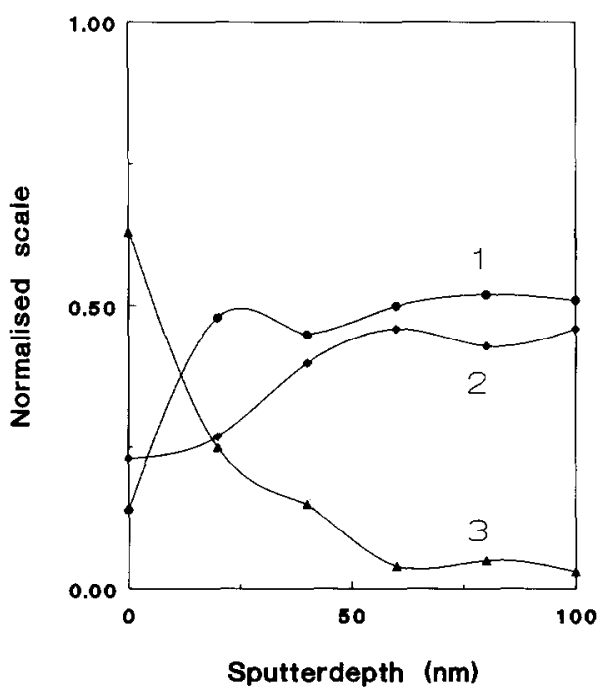

Fig. 6. SAM sputter profile of silica modified $\gamma$-alumina (1) aluminium signal, (2)oxygen signal, (3) silicon signal. The sum of the signals is normalised to one.

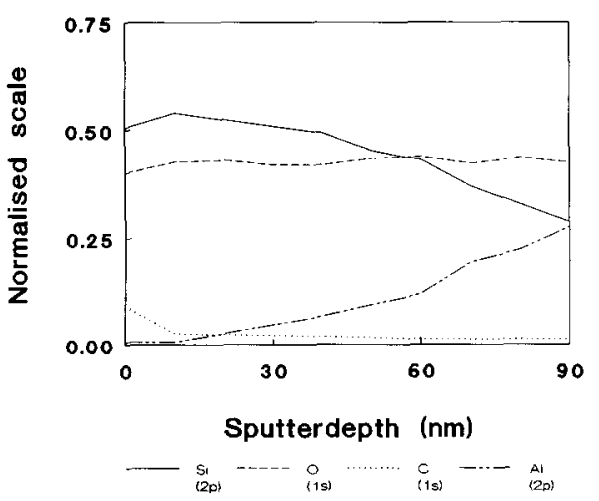

Fig. 7. XPS profile of silica modified $\gamma$-alumina. The sum of the signals is normalised to one. 
while the silicon signal drops. After about 60 $\mathrm{nm}$ no silicon is detected anymore. This simultaneous rise of aluminium content and drop of silicon content can be explained by a partial penetration of silica particles into the pores of the $\gamma$-alumina. It can be concluded that silica is present as a thin film with a thickness of at least $30 \mathrm{~nm}$ and a maximum of $60 \mathrm{~nm}$ on top of the $\gamma$-alumina. Silica particles have partially penetrated the pores.

To test the effect of this silica thin film on the gas transport properties of the whole system, the helium gas permeability was determined. Figure 8(A) presents the helium permeability for the support, the supported $\gamma$ alumina system and the silica modified $\gamma$-alumina system. It is clear that the permeability decreases considerably after modification with silica. Still the support has a certain resistance to gas phase transport and the data of the silica modified $\gamma$-alumina system should be corrected for this [21]. Figure 8(B) gives the corrected data. The permeability of the $y$-alumina thin film decreases from $12 \times 10^{-6} \mathrm{~mol} / \mathrm{m}^{2}$-sec-Pa (see Ref. [32]) before modification to $1.4 \times 10^{-6} \mathrm{~mol} / \mathrm{m}^{2}$-sec-Pa after modification with silica. Consequently the very thin silica film decreases the permeability by a factor of about 10 and the resistance to transport is almost completely caused by the silica layer. This decrease in permeability cannot be explained by a Knudsen type transport [21]. Thus, below a pore diameter of $2 \mathrm{~nm}$ other transport mechanisms are active. This conclusion is in accordance with the literature $[29,30]$ which refers to this transport regime as micropore diffusion or activated diffusion.

An elegant way to distinguish between these mechanisms and Knudsen diffusion is by the temperature dependence of the respective permeabilities. Knudsen diffusion will decrease with temperature, micropore diffusion is an activated process and will increase with temperature. Figure 9 shows the helium perme-
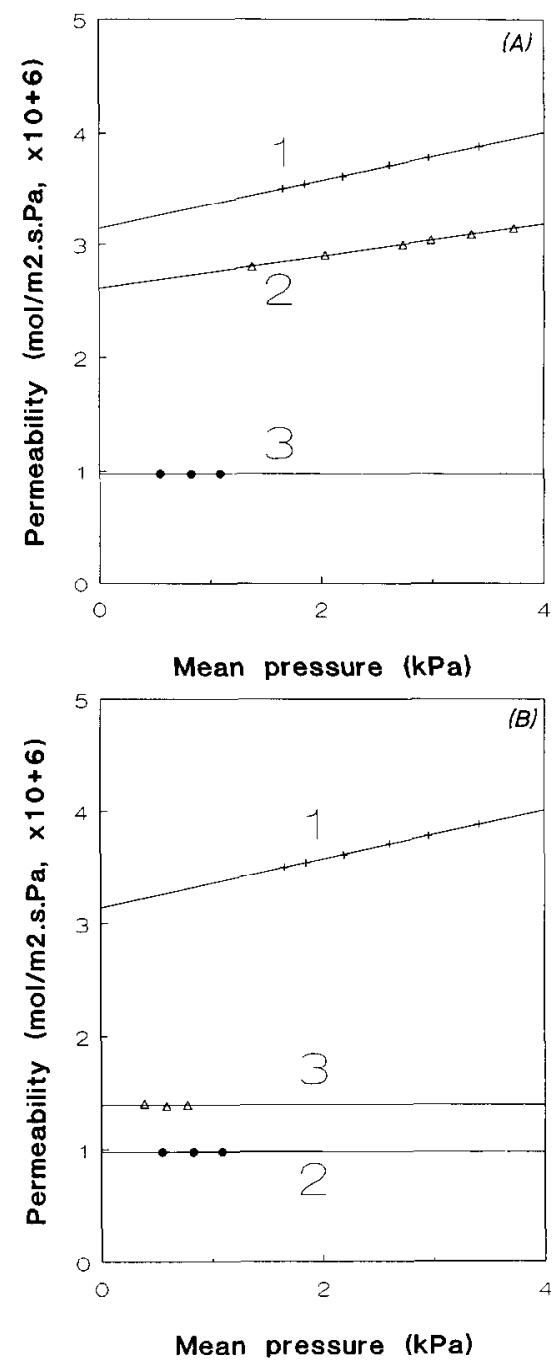

Fig. 8. (A) Helium permeability at $25^{\circ} \mathrm{C}$ for a support (1), support $+\gamma$-alumina thin film (2), and support + silica modified $\gamma$-alumina thin film (3). (B) Helium permeability at $25^{\circ} \mathrm{C}$ for a support $(1)$, support + silica modified $\gamma$ alumina thin film (2), and silica modified $\gamma$-alumina thin film, corrected for the support influence (3).

ability as a function of pressure and temperature (data are corrected for the support). It is clear that the permeability increases with temperature. The transport regime has indeed changed form Knudsen diffusion to activated diffusion. From these data an Arrhenius plot can be constructed ( $\ln F_{0}$ versus the reciprocal 


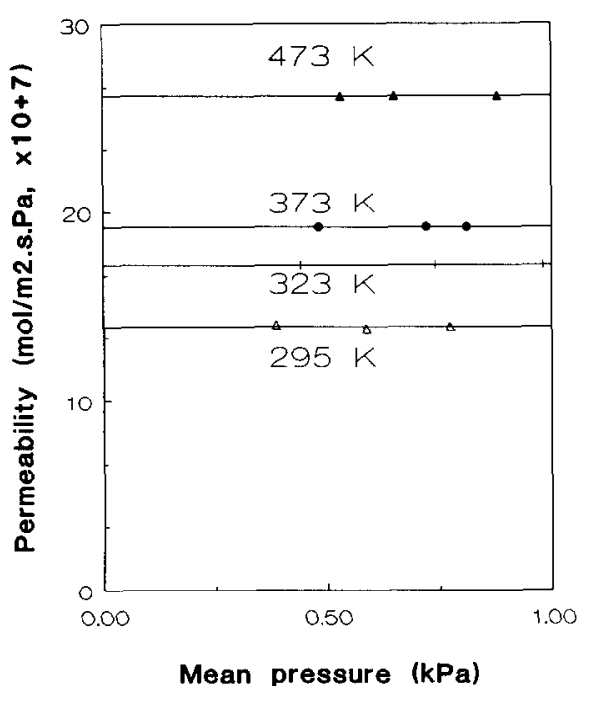

Fig. 9. Helium permeability of a silica modified $\gamma$-alumina thin film as a function of temperature (data are corrected for the support; mean pressure difference $200 \mathrm{kPa}$ ).

temperature ). An activation energy of $4 \mathrm{~kJ} / \mathrm{mol}$ is calculated for the helium permeability. The activation energy for helium transport through non-porous glass is around $21 \mathrm{~kJ} / \mathrm{mol}$ [31]. This much higher value indicates that the helium is transported through micropores in the silica thin film. Very recently helium transport through microporous modified glass membranes was reported [29] and an activation energy of $4 \mathrm{~kJ} / \mathrm{mol}$ was given for this activated transport.

Figure 10 presents permeability data for several gases with corrections made for the support. As could be expected the ratio between the gases does not reflect the mass ratio, as expected for Knudsen type behavior. Presumably all gases show activated transport. To test this, permeabilities were also determined as a function of temperature. In all cases a negligible dependence of the permeability on pressure was found. Therefore Table 4 presents the (mean) permeability as a function of temperature only. The permeability of propylene was not detectable in our equipment (permeability $<3 \times 10^{-8}$ $\mathrm{mol} / \mathrm{m}^{2}$-sec-Pa). The $\mathrm{CO}_{2}$ permeability does

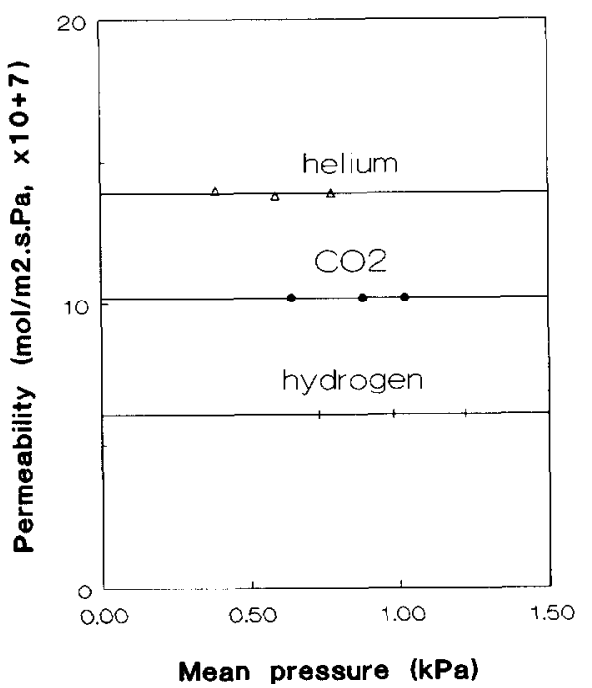

Fig. 10. Permeability of several gases of a silica modified $\gamma$ alumina thin film al room temperature (data corrected for the support). Propylene permeability was too low to be detected.

\section{TABLE 4}

Permeability of several gases through a silica modified $\gamma$ alumina system as a function of temperature; activation energies (calculated from an Arrhenius plot) are $4 \mathrm{~kJ} / \mathrm{mol}$ for helium and $10 \mathrm{~kJ} / \mathrm{mol}$ for hydrogen

\begin{tabular}{lll}
\hline Gas & $\begin{array}{l}\text { Temperature } \\
(\mathrm{K})\end{array}$ & $\begin{array}{l}\text { Permeability } \\
{\left[\mathrm{mol} / \mathrm{m}^{2} \text {-sec-Pa }(\mathbf{x 1 0})\right]}\end{array}$ \\
\hline $\mathrm{He}$ & 295 & 14 \\
& 323 & 17 \\
& 373 & 19 \\
& 473 & 26 \\
$\mathrm{H}_{2}$ & 295 & 6 \\
& 373 & 19 \\
$\mathrm{CO}_{2}$ & 473 & 26 \\
& 295 & 10 \\
& 373 & 10 \\
$\mathrm{C}_{3} \mathrm{H}_{6}$ & 473 & 9 \\
\hline
\end{tabular}

not depend on temperature at all. The helium and hydrogen permeabilities are activated with activation energies of $4 \mathrm{~kJ} / \mathrm{mol}$ and $10 \mathrm{~kJ} / \mathrm{mol}$, respectively. Thus the $\mathrm{CO}_{2}$ needs a smaller amount of energy to permeate, helium and hydrogen need increasingly more and propylene 
seems to be excluded by the silica thin film. These effects can only be explained by strong interaction with the silica matrix and/or by size exclusion.

A qualitative picture of transport of molecules through very small pores is given in Fig. 11. It is partly based on a model by Koresh and Soffer [33-35]. They developed carbon molecular sieves of which the pore diameter could be controlled between 0.33 and $0.52 \mathrm{~nm}$ and described transport of gases through these carbon molecular sieves based on analysis of potential energy profiles of a molecule in a very small pore. Figure 11 presents a qualitative model of the potential energy $E$ of a molecule in a pore of varying dimensions. The molecule-wall interactions will be considered. If the walls are far apart (Fig. 11A) potential minima near the wall occur, due to attractive forces of the molecule-(single) wall interaction. These poten- tial minima start to overlap when the walls are brought together (Fig. 11B) and finally overlap completely (Fig. 11C). This gives rise to one potential minimum due to (attractive) interaction between the molecule and both walls. As the walls come even closer to each other, the minimum is raised due to the overlap of the repulsive portions of the molecule-wall interaction (Fig. 11D) until the pore becomes impermeable (Fig. 11E).

Figure 11 takes only the size effects of the molecule into account. Naturally attractive and repulsive forces of a different nature can also exist. These specific interactions (e.g. dipoledipole interaction) should be added to the potential energy curves as presented in Fig. 11. In Fig. 12 a (random) attractive force is added to the case of fig. 11B. Figure 12 shows that specific interaction can lower the potential minima (Fig. 12A) as well as increase these min-

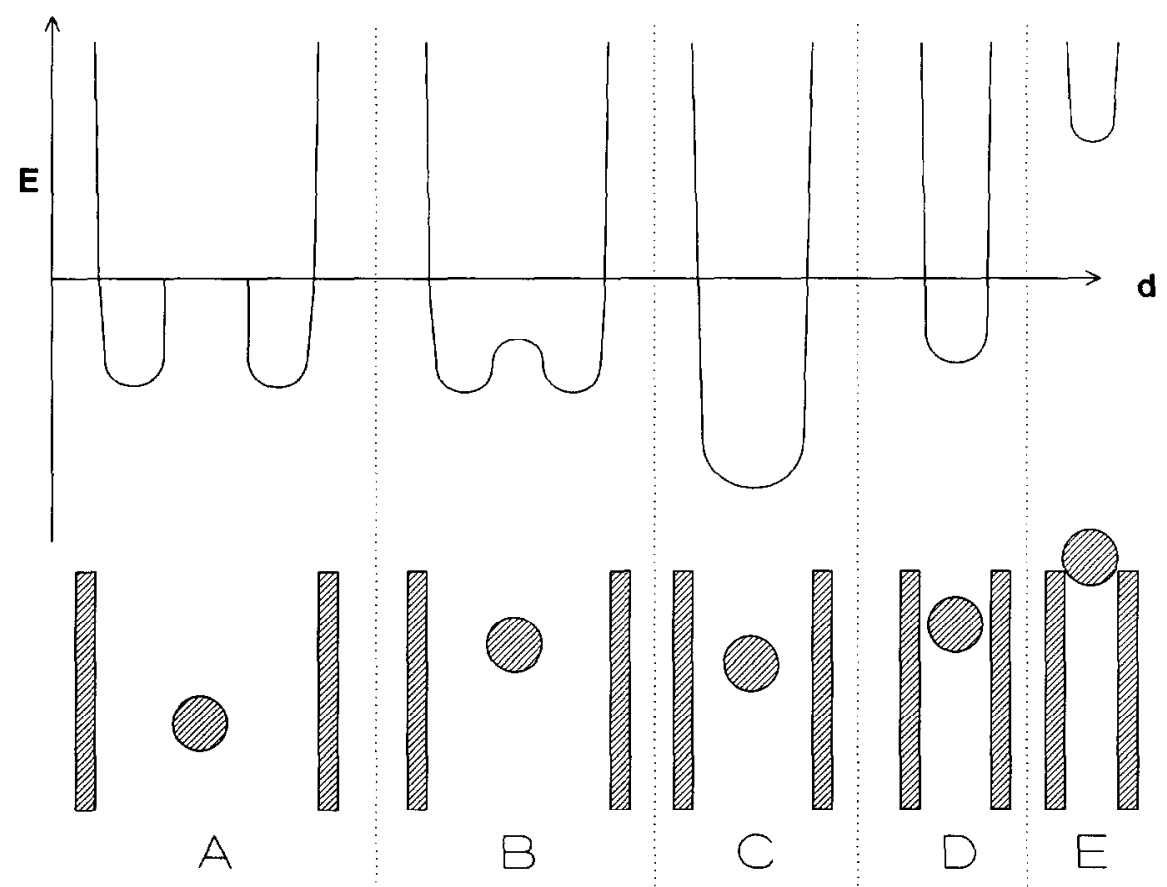

Fig. 11. Potential energy $E$ of a molecule of radius $r$ as a function of distance $d$ between the walls. (A) distance $\geqslant 2 \mathrm{~nm}$, (B) distance 1-2 nm, (C) distance 2-3 molecular diameters, (D) distance 1-2 molecular diameters, (E) distance $\leqslant 1$ molecular diameter. 


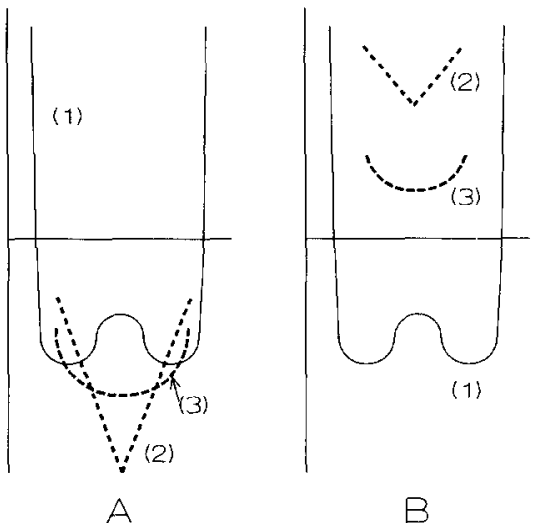

Fig. 12. Interaction energy plotted against the distance $d$ between the pore walls for the case of Fig. 11(B) with an additional attractive potential (A) or repulsive potential (B), (1) Potential of Fig. 11(B), (2) specific interaction, (3) resultant curve.

ima (Fig. 12B). In this way it is possible to make a pore effectively impermeable to a molecule even if the size of the molecule permits its entrance in the pore.The qualitative picture of Figs. 11 and 12 shows that in pores with molecular dimensions, the size of the gas molecule and specific molecule-wall interactions can lead to distinct differences in potential energy barrier and therefore in transport rate. These short range interactions become important when the pore diameter is not larger than approximately 3 times the molecule diameter [33,36].

Based on adsorption studies [33] and estimation of molecular dimensions [34], Koresh and Soffer found that $\mathrm{CO}_{2}$ behaves as a smaller molecule than $\mathrm{H}_{2}$. This is in agreement with the activation energies found for these gases in the silica thin film. In a later study [34] they found that if $\mathrm{CO}_{2}$ is transported, helium is also transported. Okubo and Inone [29,36], however, found that helium showed activated transport in microporous glass, very similar in chemical nature to the silica thin films. $\mathrm{CO}_{2}$ did not show any activated transport in these experiments. A specific interaction between $\mathrm{CO}_{2}$ and the silica surface can explain this phenom- enon. The exclusion of propylene is probably due to strong repulsive forces between the molecule and the silica wall and/or to its size. It is suggested that the permeability data can be qualitatively understood in terms of molecule size and specific molecule-wall interactions. The pore diameter in the silica thin film should then be smaller than approximately $1.0 \mathrm{~nm}$, since the mean molecular diameter is $0.3 \mathrm{~nm}$ for the gases studied.

The strong interaction between molecule and pore wall at small pore diameters is sensitive to slight changes in structure or chemical environment. This may offer a possible explanation for the difference between the first permeability data [32] and those obtained later. It also offers the possibility of introducing very specific gas selectivities, e.g. by changing the chemical environment slightly. Further research of these phenomena is needed.

Since the permselectivities for the gases studied are quite good (Table 4), especially the very low permeability of propylene relative to that of hydrogen, separation experiments were performed with a $\mathrm{H}_{2}-\mathrm{C}_{3} \mathrm{H}_{6}$ mixture at various temperatures. In separation experiments the limit for detection of the permeability is lower than that in permeability experiments due to the more sensitive analysis technique (gas chromatography). It is to be expected that propylene can be detected in the separation experiments. The separation factor as a function of temperature is given in Table 5, together with the gas compositions. The composition of the feed flow along the membrane surface was constant. Table 5 shows that the separation factor can reach 100 and higher. In these separation experiments at elevated temperatures the hydrogen composition in the permeate mixture is over $90 \%$, starting with less than $10 \%$ in the feed mixture. At $260{ }^{\circ} \mathrm{C}$ (temperature limit of the sealing material of the separation equipment) no propylene could be detected anymore.

The very high separation factors support the 


\section{TABLE 5}

Separation factors and compositions of feed and permeate of a $\mathrm{H}_{2}-\mathrm{C}_{3} \mathrm{H}_{6}$ mixture under a pressure gradient of approximately 3 bar as a function of temperature [seperation factors are defined by $y(1-x) /(x(1-y))$ with $x$ and $y$ the molar fraction of the fastest permeating component in feed and permeate respectively]

\begin{tabular}{lllllll}
\hline $\begin{array}{l}\text { Temperature } \\
(\mathrm{K})\end{array}$ & $\begin{array}{l}\text { Feed } \\
\text { composition }\end{array}$ & & \multicolumn{2}{l}{$\begin{array}{l}\text { Permeate } \\
\text { composition }\end{array}$} & $\begin{array}{l}\text { Separation } \\
\text { factor }\end{array}$ \\
\cline { 2 - 3 } & & $\% \mathrm{H}_{2}$ & $\% \mathrm{C}_{3} \mathrm{H}_{6}$ & $\% \mathrm{H}_{2}$ & $\% \mathrm{C}_{3} \mathrm{H}_{6}$ & \\
\hline 295 & 9.5 & 90.5 & & 58.5 & 41.5 & 13.4 \\
& 60.8 & 39.2 & 96.0 & 4.0 & $15.5^{\mathrm{b}}$ \\
373 & 9.3 & 90.7 & 86.5 & 13.5 & 62 \\
473 & 9.1 & 90.9 & 94.0 & 6.0 & 156 \\
533 & 9.2 & 90.8 & $>96.5$ & $<3.5$ & $>272^{\mathrm{c}}$ \\
\hline
\end{tabular}

aFeed flow of constant composition.

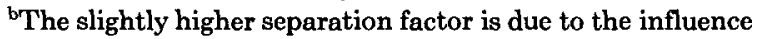
of process parameters.

'No propylene could be detected, the minimum obtainable propylene signal was used in calculation.

hypothesis that the silica thin film contains pores of molecular dimension. The increase in separation factor with temperature is caused by increasing hydrogen permeability and decreasing propylene permeability, as indicated by the gas chromatography data. The propylene permeability at room temperature is probably attributed to a few larger pores in the silica thin film through which Knudsen transport of the propylene takes place. The increase in temperature leads to a decrease of Knudsen diffusion transport and thus a decrease of the propylene permeability. A similar transport behavior of $\mathrm{N}_{2}$ was observed by Gavalas et al. [37]. In their experiments a silica layer of $160 \mathrm{~nm}$, presumably dense, was deposited in the pores of a $\mathrm{Vy}$ cor glass membrane by chemical vapor deposition. Activated hydrogen transport was observed (activation energy $25 \mathrm{~kJ} / \mathrm{mol}$ ). The nitrogen permeability decreased with temperature. This was explained by assuming the presence of a few larger pores, through which the nitrogen was transported by Knudsen dif- fusion. This contribution decreased with increasing temperature, completely in agreement with the observations for the silica thin film in Table 5 . It can be concluded that the very high separation factor, which increases with temperature, also indicates the presence of pores of molecular dimensions (diameter $<1.0 \mathrm{~nm}$ ) in the silica thin film.

It is not possible to obtain directly an accurate pore diameter of the supported silica films, but an estimate is possible. For this purpose Table 6 compares several different permeability data obtained with microporous inorganic materials. The permeabilities are corrected for the influence of the layer thickness and can be directly compared. Comparison of the silica membranes in Table 6 (nos. 1-3) shows that the silica membranes described in this article have the highest permeability. The permeability data seem to indicate the presence of relatively large micropores (around $1.0 \mathrm{~nm}$ diameter) in the silica thin films described in this article.

The carbon molecular sieves show a higher permeability, especially for helium (Table 6). The pores of the carbon molecular sieves are visualised as channels of considerable size with constrictions of molecular dimensions [34, $35,38]$. The large channels provide the high permeability, the constrictions provide the selectivity. Since the permeability is only slightly higher than that in the silica thin films, this suggests that the micropores in the silica film are large. Table 6 therefore suggests, that the micropores in the supported silica thin films are near $1 \mathrm{~nm}$ diameter, considering the high permeabilities. The high selectivities are due to short range specific interactions. This suggestion implies that it is possible to control the separation properties of these membranes by chemical modification of the surface, giving rise to proper specific interactions between the silica surface and a gas molecule. Finally Table 7 shows that the product of permeability and se- 
TABLE 6

Comparison of permeabilities for several gases and membrane systems at several temperatures after correction for differences in layer thickness

\begin{tabular}{|c|c|c|c|c|c|c|}
\hline Nr. & Membrane system & Author [Ref.] & $\begin{array}{l}\text { Layer } \\
\text { thickness }\end{array}$ & Gas & $\begin{array}{l}\text { Temperature } \\
\text { (K) }\end{array}$ & $\begin{array}{l}\text { Permeability } \\
\left(\mathrm{mol}-\mathrm{m} / \mathrm{m}^{2} \text {-sec-Pa }\right)\end{array}$ \\
\hline 1 & $\begin{array}{l}\text { Silica modified } \\
\text { glass membrane }\end{array}$ & Megiris [37] & $200 \mathrm{~nm}$ & $\mathrm{H}_{2}$ & 723 & $2 \times 10^{-15}$ \\
\hline 2 & $\begin{array}{l}\text { Silica modified } \\
\text { glass membrane }\end{array}$ & $\begin{array}{l}\text { Okubo } \\
{[29,36]}\end{array}$ & $\pm 500 \mathrm{~nm}$ & $\begin{array}{l}\mathrm{H}_{2} \\
\mathrm{He} \\
\mathrm{CO}_{2}\end{array}$ & $\begin{array}{l}523 \\
523 \\
523\end{array}$ & $\begin{array}{l}2.5 \times 10^{-15} \\
2.0 \times 10^{-15} \\
4 \times 10^{-16}\end{array}$ \\
\hline 3 & $\begin{array}{l}\text { Silica modified } \\
\gamma \text {-alumina }\end{array}$ & Uhlhorn [this paper] & $60 \mathrm{~nm}$ & $\begin{array}{l}\mathrm{H}_{2} \\
\mathrm{He} \\
\mathrm{CO}_{2}\end{array}$ & $\begin{array}{l}473 \\
373 \\
373\end{array}$ & $\begin{array}{r}1 \times 10^{-13} \\
7 \times 10^{-14} \\
32 \times 10^{-15}\end{array}$ \\
\hline 4 & $\begin{array}{l}\text { Carbon molecular } \\
\text { sieve }\end{array}$ & $\begin{array}{l}\text { Koresh } \\
{[33-35]}\end{array}$ & $6 \mu \mathrm{m}$ & $\begin{array}{l}\mathrm{H}_{2} \\
\mathrm{He} \\
\mathrm{CO}_{2}\end{array}$ & $\begin{array}{r}773 \\
1123 \\
1123\end{array}$ & $\begin{array}{l}24 \times 10^{-14} \\
16 \times 10^{-13} \\
84 \times 10^{-15}\end{array}$ \\
\hline
\end{tabular}

TABLE 7

Permeabilities (not corrected for the layer thickness) and selectivities for the membranes of Table 6 and the separation power (product of permeability and selectivity). The numbers correspond to those in Table 6

\begin{tabular}{lllccr}
\hline Nr. & Gas mixture & $\begin{array}{l}\text { Temperature } \\
(\mathrm{K})\end{array}$ & $\begin{array}{l}\text { Selectivity } \\
(-)\end{array}$ & $\begin{array}{l}\text { Permeability } \\
{\left[\mathrm{mol} / \mathrm{m}^{2} \text {-sec-Pa }\right.} \\
\left.\left(\times 10^{8}\right)\right]\end{array}$ & $\begin{array}{l}\text { Separation } \\
\text { power }\end{array}$ \\
\hline 1 & $\mathrm{H}_{2}-\mathrm{N}_{2}\left(\mathrm{H}_{2}\right)$ & 723 & 2000 & 1 & 2000 \\
2 & $\mathrm{H}_{2}-\mathrm{Ar}\left(\mathrm{H}_{2}\right)$ & 523 & 24 & 0.5 & 12 \\
3 & $\mathrm{H}_{2}-\mathrm{C}_{3} \mathrm{H}_{6}\left(\mathrm{H}_{2}\right)$ & 473 & 160 & 161 & 25760 \\
4 & $\mathrm{He}_{-}-\mathrm{N}_{2}(\mathrm{He})$ & 1123 & 22 & 27 & 594 \\
\hline
\end{tabular}

${ }^{\text {a }}$ Fastest permeating component between brackets.

b $O$ fastest permeating component.

lectivity is among the highest ever reported. This is due to the presence of micropores and the very small silica layer thickness.

To conclude this article, two important remaining questions are now addressed:

-The first is whether or not the transport properties can be directed towards a certain application by controlling the synthesis parameters. -The second is how exposure to water vapor influences the microstructural characteristics of the silica modified $\gamma$-alumina system. Only very preliminary data are given, since studies have just started.

Table 8 presents permeability and separation data of a silica modified $\gamma$-alumina system. In this case $3 \mathrm{ml}$ of additional water was added in the synthesis. Tables 1 and 2 show that this decreases the surface area. This is probably due to a larger amount of very small pores $(<0.4$ $\mathrm{nm}$ ), impenetrable for the argon molecule. Table 8 shows the same trend. The activation energies for transport are large compared to 
TABLE 8

The permeability, its activation energy (obtained from an Arrhenius plot) and the separation factor for a $\mathrm{CO}_{2}-\mathrm{CH}_{4}$ mixture at several temperatures for several gases through a silica modified $\gamma$-alumina system made by an alternative synthesis procedure $(3 \mathrm{ml}$ water extra added)

\begin{tabular}{lllll}
\hline Gas & $\begin{array}{l}\text { Temperature } \\
(\mathrm{K})\end{array}$ & $\begin{array}{l}\text { Permeability } \\
{\left[\mathrm{mol} / \mathrm{m}^{2} \text {-sec-Pa }\left(\times 10^{7}\right)\right]}\end{array}$ & $\begin{array}{l}\text { Activation energy } \\
(\mathrm{kJ} / \mathrm{mol})\end{array}$ & Separation factor \\
\hline $\mathrm{He}$ & 295 & 12 & 9 \\
& 373 & 28 & & \\
$\mathrm{H}_{2}$ & 473 & 48 & 11 & \\
& 295 & 7 & 10 & $48^{\mathrm{a}}$ \\
$\mathrm{CO}_{2}$ & 373 & 19 & - & $65^{\mathrm{a}}$ \\
& 473 & 39 & - & $28^{\mathrm{a}}$ \\
$\mathrm{CH}_{4}$ & 295 & 4 & & \\
\hline
\end{tabular}

${ }^{\mathrm{a}} \mathrm{CO}_{2}$ preferentially permeating component.

those in Table 5. Also $\mathrm{CO}_{2}$ transport is now activated, indicating that higher energies are required for transport. A separation experiment with a $\mathrm{CO}_{2} / \mathrm{CH}_{4}$ mixture was performed. Again high separation factors were obtained. In this case however the separation factor decreases at elevated temperatures, probably due to a high activation energy of methane. Still Table 8 shows that it is possible to influence the microstructure and thus the separation properties by changing the synthesis parameters. Although this offers numerous prospects and is therefore part of our current research program, it is stressed that the understanding of the interaction between synthesis parameters, resulting microstructure and transport and separation properties is still in its infancy.

The largest drawback of silica is its sensitivity towards water. Table 2 already showed that if silica non-supported thin films are exposed to ambient air, they densify. Recent literature on the sensitivity of a silica thin film incorporated in a Vycor glass matrix shows [39] that this silica film densifies, shrinks and cracks under the influence of water. This process is accelerated at high temperatures [8]. Prelimi- nary experiments with silica modified $\gamma$ alumina systems, exposed to ambient air at room temperature, also indicate that silica densifies to a certain extent. This leads to shrinkage of the film and can introduce defects. The separation efficiency decreases. This problem and possible solutions are now a major subject of present research.

\section{Conclusions}

(1) Silica and titania microporous thin films can be made by the polymeric gel route. The average pore diameter in non-supported silica thin films is $1.5 \mathrm{~nm}$, as determined by argon adsorption.

(2) Silica is X-ray amorphous and thermally stable to $900{ }^{\circ} \mathrm{C}$. Titania is thermally stable to $350^{\circ} \mathrm{C}$. Above this temperature enhanced particle growth causes pore growth. The microporosity disappears.

(3) Silica modified $\gamma$-alumina systems should be made in a very controlled procedure in order to obtain reproducible data. The silica is present as a very thin film on top of the $\gamma$-alumina. The thickness of the silica film on top of the $\gamma$ - 
alumina film is at least $30 \mathrm{~nm}$ and maximum $60 \mathrm{~nm}$. Silica particles have partially penetrated the pores.

(4) The permeability of helium and hydrogen through the silica modified $\gamma$-alumina system is activated. The transport mechanism is micropore diffusion or activated diffusion. The permeability of propylene is negligible.

(5) The order of the permeability of several gases in the activated transport seems to indicate the presence of pores of molecular dimension in the silica thin film and specific interactions between molecule and (both) pore walls.

(6) The separation factor of a $\mathrm{H}_{2}-\mathrm{C}_{3} \mathrm{H}_{6}$ mixture can become as high as 200 at $260^{\circ} \mathrm{C}$. This very high selectivity also indicates the presence of specific interaction and pores of molecular dimension in the silica thin film.

(7) The high permeabilities in comparison to other microporous materials indicate a pore diameter around $1.0 \mathrm{~nm}$ in the supported silica thin films. The product of permeability and selectivity is among the highest ever reported.

(8) Although changing the synthesis parameters results in optimisation of separation properties, the understanding of the interaction between synthesis parameters, resulting microstructure and transport and separation properties is still in its infancy.

\section{References}

1 A.F.M. Leenaars, K. Keizer and A.J. Burggraaf, The preparation and characterization of alumina membranes with ultrafine pores. 2 . The formation of supported membranes, J. Colloid Interface Sci., 105 (1985) 27-40.

2 R.J.R. Uhlhorn, K. Keizer and A.J. Burggraaf, Synthesis of ceramic membranes. Part I. Synthesis of nonsupported and supported $\gamma$-alumina membranes without defects, J. Mater. Sci., 27 (1992), in press.

3 R.J.R. Uhlhorn, K. Keizer and A.J. Burggraaf, Synthesis of ceramic membranes. Part II. Modification of thin alumina films : reservoir method, J. Mater. Sci., 27 (1992), in press.
4 K. Keizer, R.J.R. Uhlhorn, R.J. Van Vuren and A.J. Burggraaf, Gas separation mechanisms in microporous modified $\gamma$-alumina membranes, J. Membrane Sci., 39 (1988) 285-301.

5 R.J.R. Uhlhorn, K. Keizer and A.J. Burggraaf, Gas and surface diffusion in modified $\gamma$-alumina systems, J. Membrane Sci., 46 (1989) 225-241.

6 R.J.R. Uhlhorn, K. Keizer and A.J. Burggraaf, Gas transport and separation with ceramic membranes. Part I. multilayer diffusion and capillary condensation, J. Membrane Sci., 66 (1992) 259.

7 K.S.W. Sing (Ed.), IUPAC report: Reporting physisorption data for gas/solid systems (recommendations 1984), Pure Appl. Chem., 57(4) (1985) 603.

8 R.K. Iler, The Chemistry of Silica, Wiley, New York, NY, 1979.

9 V.T. Zaspalis, Catalytically active ceramic membranes: synthesis, properties and reactor applications, Ph.D Thesis, University of Twente, Enschede, 1990.

10 Q. Xu and M.A. Anderson, Preparation of titania membranes, Mat. Res. Soc., Symp. Proc., 132 (1989) 41-46.

11 J.D. McKenzie and D.R. Ulrich (Eds.), Ultrastructure Processing of Advanced Ceramics, Wiley, New York, NY 1988.

12 C.J. Brinker, D.E. Clark and D.R. Ulrich (Eds.), Better Ceramics through Chemistry, Part I-III, Wiley, New York, NY, 1988.

13 R.J.P. Corriu, D. Leclercq, A. Vioux, M. Pauthe and J. Phalippou, Some new possibilities for the preparation of silica gels, in: J.D. McKenzie and D.R. Ulrich (Eds.), Ultrastructure Processing of Advanced Ceramics, Wiley, New York, NY, 1988, pp. 113-127.

14 S. Sakka, H. Kozuka and S.-H. Kim, Various factors affecting the conversion of silicon alkoxide solutions to gels, in: J.D. McKenzie and D.R. Ulrich (Eds. ), Ultrastructure Processing of Advanced Ceramics, Wiley, New York, NY, 1988, pp. 159-173.

15 K.D. Keefer, The effect of hydrolysis conditions on the structure and growth of silicate polymers, in: C.J. Brinker, D.E. Clark and D.R. Ulrich (Eds), Better Ceramics through Chemistry, Part I-III, Wiley, New York, NY, 1988, pp. 15-24.

16 C.J. Brinker, K.D. Keefer, D.W. Schaeffer and C.S. Ashley, Sol-gel transitions in simple silicates. I., J. Non-Cryst. Solids, 48 (1982) 47-64.

17 C.J. Brinker, K.D. Keefer, D.W. Schaeffer, T.A. Assink, B.D. Kay and C.S. Ashley, Sol-gel transitions in simple silicates. II, J. Non-Cryst. Solids, 63 (1984) 45-59.

18 U. Bräutigam, H. Bürger and W. Vogel, Factors affecting the stability of silica gels, J. Non-Cryst. Solids, 110 (1989) 163-169. 
19 C.J. Brinker, A.J. Hurd and K.J. Ward, Fundamentals of sol-gel film formation, in: J.D. McKenzie and D.R. Ulrich (Eds.), Ultrastructure Processing of Advanced Ceramics, Wiley, New York, NY, 1988. pp. 223241.

20 C.J. Brinker, A.J. Hurd, G.C. Frye, K.J. Ward, C.S. Ashley, J. Non-Cryst. Solids, to be published.

21 R.J.R. Uhlhorn, Ceramic membranes for gas separation: synthesis and transport properties, $\mathrm{Ph} . \mathrm{D}$ thesis, University of Twente, 1990.

22 J. Livage, M. Henry, A predictive model for inorganic polymerization reactions, in: J.D. McKenzie and D.R. Ulrich (Eds.), Ultrastructure Processing of Advanced Ceramics, Wiley, New York, Ny, 1988. pp. 183-197.

23 K.S.W. Sing (Ed.), Characterization of Porous Solids, ACS, Washington, DC, 1988.

24 M.M. Dubinin and V.A. Ashtakov, Development of theories on the volume filling of micropores during the adsorption of gases and vapors by microporous adsorbents, Adv. Chem., 102 (1971) 69.

25 M.M. Dubinin and L.V. Radushkevitch, Methods of reduction of adsorption isotherms and the specific surface area of adsorbents, Proc. Acad. Sci. USSR, 56 (1976) 391.

26 M.J.G. Jansen and C.W.M. van Oorschot, The characterization of zeolites by gas adsorption, in: P.A. Jacobs and R.A. van Santen (Eds.), Zeolites, Facts and Figures, Elsevier, Amsterdam, 1989, pp. 633-642.

27 D. Briggs and M.P. Seah (Eds.), Practical Surface Analysis by Auger and X-Ray Spectroscopy, Wiley, New York, NY, 1983.

28 J.T. Grant, Surface analysis with Auger electron microscopy, Appl. Surf. Sci., 13 (1982) 35-62.

29 T. Okubo and H. Inoue, Single gas permeabilities through porous glass modified with tetra ethoxy silane, AICh E J., 35(5) (1989) 845-848.
30 R.E. Cunningham and R.J.J. Williams, Diffusion in Gases and Porous Media, Plenum Press, New York, NY, 1980.

31 V.O. Altemose, Helium diffusion through glass, J. Appl. Phys., 32 (1961) 1309.

32 R.J.R. Uhlhorn, M.H.B.J. Huis in 't Veld, K. Keizer and A.J. Burggraaf, High permselectivities of microporous silica-modified $\gamma$-alumina membranes, J. Mater. Sci. Lett., 8 (1989) 1135-1138.

33 J.E. Koresh and A. Soffer, Study of molecular sieve carbons. Part I: Pore structure, gradual pore opening and mechanisms of molecular sieving, J. Chem. Soc. Faraday. Trans., 76(2) (1980) 2457-2471.

34 J.E. Koresh and A. Soffer, Study of molecular sieve carbons. Part II. Estimation of cross sectional diameters of non-spherical molecules, J. Chem. Soc. Faraday. Trans., 76 (2) (1980) 2472-2485.

35 J.E. Koresh and A. Soffer, Molecular sieve carbon permselective membranes. Part I. Presentation of a new device for gas mixture separation, Sep. Sci. Technol., 18(8) (1983) 723-734.

36 T. Okubo and H. Inoue, Introduction of specific gas selectivity to porous glass membranes by treatment with tetra ethoxy silane, J. Membrane Sci., 42 (1989) 109.

37 G.R. Gavalas, C. Megiris and S.W. Nam, Deposition of $\mathrm{H}_{2}$ permselective silica films, Chem. Eny. Sci., 44(9) (1989) 1829-1835.

38 J.E. Koresh and A. Soffer, The carbon molecular sieve membranes. General properties and the permeability of $\mathrm{CH}_{4} / \mathrm{H}_{2}$ mixture, Sep. Sci. Technol., 22 (2) (1987) 973-982.

39 S.W. Nam and G.R. Gavalas, Stability of $\mathrm{H}_{2}$ permselective silica films, in: Membrane Reactor Technology (R. Govind and N. Itoh (Eds.) ), AICh. E Symp. Ser. No. 268, Vol. 85, 1989, pp. 68-74. 